\title{
OPTIMIZATION AND NANOREINFORCEMENTS OF LUBRICANT CONCENTRATION FOR STEEL SHEET FORMING PROCESS
}

\author{
Jaime Taha-Tijerina ${ }^{1,2}$, Ruben Calderón ${ }^{1}$, Bárbara Rodriguez ${ }^{1}$ \\ ${ }^{1}$ Departamento de Ingeniería, Universidad de Monterrey \\ Av. Morones Prieto 4500 Pte., San Pedro Garza García, México, 66238 \\ ${ }^{2}$ Engineering Technology Department, \\ University of Texas Rio Grande Valley, Brownsville, TX, USA, 78520 \\ Corresponding author: Jaime Taha-Tijerina, jose.taha@udem.edu
}

\begin{abstract}
In metal-mechanic industry, lubricants are applied to improve products' quality and tools useful life, while reducing friction and wear, also removing the generated heat during the material processing. Tribological evaluations are performed varying the water content of two widely used lubricants in automotive metal-forming operations. Evaluations are first performed to determine the optimal lubricant dilutions, followed by reinforcement of 2Dnanostructures of hexagonal Boron Nitride (h-BN). Tribological characterization under extreme pressures (EP) are performed with a four-ball tribometer according to the Institute for Sustainable Technologies -National Research Institute (ITeE-PIB) Polish method under scuffing conditions. The optimized concentrations are determined for Ecodraw and Montgomery lubricants, representing a 28\% and 3\% improvement in pressure loss limit at 1:8 and 1:6 concentrations, respectively. Block-on-ring tribotest is used to determine the coefficient of friction (COF) of the optimized lubricant dilutions and h-BN nanolubricants, which represent $\sim 10 \%$ improvement. These results could be attributed to diverse factors such as a layering mechanism of the 2D nanostructures, soft van der Waals forces between 2D h-BN layers, and the deposition of h-BN on the worn surface, decreasing the shearing stress and COF. Finally, thermal conductivity evaluations showed an enhancement by $30 \%$ and $15 \%$ with addition of $\mathrm{h}-\mathrm{BN}$, demonstrating the potential of 2D nanostructures for improving the efficiency on antiwear and thermal transport.
\end{abstract}

Key words: Lubricants, Dilutions, Plastic Deformation, hexagonal boron nitride, Thermal conductivity.

\section{INTRODUCTION}

Metal-mechanic industry, such as stamping, punching, hydroforming, among other manufacturing processes particularly on automotive industry, deals with several issues concerning tooling and working pieces in constant contact, friction and wear, and the effects of generated heat, thermal transport and loading pressures; particularly in deep-drawing operations such as in automotive forming applications (stamping, hydroforming, rollforming, among others) [1,2]. Metal-forming lubricants provide reduction in friction and wear among components, dissipating heat and maintaining good quality of the working products. With aid of proper lubrication and components design, these kind of manufacturing processes have been improved under extreme working conditions.

Another critical aspect in industry is that due to increments in raw material and operative costs, a great benefit has been found when lubricants are diluted. These diluted lubricants still possess good characteristics and properties, maintaining a good quality of the final processed products. Furthermore, the diluted lubricants could contribute to environment, in the sense of not disposing large quantities of these materials as fast as they could be if no dilution were done [3]. It could also contribute to an easy cleaning of the working pieces and workstations.

On the other hand, incorporation of solid nanostructures has been investigated to improve the tribological characteristics of lubricant systems, such as load-carrying capacity, coefficient of friction (COF) and wear, among others [4-8]. Due to morphology and configuration (small size, $<100 \mathrm{~nm}$ ), nanostructures may be able to provide a polishing effect [9], mending effect [9], functioning as nanobearings or tribo-films [10,11], decreasing contact pressures to have larger surface contact areas [12], among others $[13,14]$.

Two dimensional nanostructures (2D) obtained remarkable scientific attention due to their unique physical, chemical and mechanical properties [15]. Among these novel 2D materials, hexagonal boron nitride (h-BN) which is a ceramic material in powder form is a very well-known solid lubricant who has attracted attention due to its outstanding properties, such as friction reduction and anti-wear promotion, tribofilm formation behavior, superb thermal conductivity, mechanical stability [16,17]. Moreover, 
h-BN is environmentally friendly and inert to most of the chemicals which make them appealing for most of the tribological applications.

Investigations focused on $\mathrm{h}-\mathrm{BN}$ nanostructures confirm the benefits and effects on tribological behavior. Wan et al. [18] observed a significant improvement in antifriction performance of $15 \mathrm{~W}-40$ oil reinforced with h-BN nanoparticles. Celik et al. [19]studied SAE 10W engine oil reinforced with hBN. In their results, they obtained reductions in friction and wear characteristics of of $14 \%$ and $65 \%$, respectively, when compared to pure oil. Similarly,

Río et al. [20] obtained 20\% reduction in antifriction and antiwear behavior of poly-alpha-olefin / h-BN nanostructures under pure sliding conditions at merely $0.75 \mathrm{wt} . \%$.

On other applications, h-BN nanostructures are environmentally and skin friendly [21,22]; $\mathrm{BN}$ is widely used as main ingredient for cosmetics and other human-related skin, eye area, or mucous membranes applications.

For this work, the tribological performance of lubricants applied in plastic deformation metalforming manufacturing processes with varying dilution concentrations were analysed. Additionally, evaluations on the optimized diluted concentrations of lubricants were reinforced with $0.10 \mathrm{wt} . \%$ of $2 \mathrm{D} \mathrm{h}$ BN nanostructures. Tribological evaluations are performed under extreme pressure (EP) condition with a four-ball tribotester and block-on-ring configuration. Load-carrying capacity and coefficient of friction (COF) are evaluated and compared among metal-mechanic forming nanolubricants. Thermal conductivity is obtained using a KD2 Pro (Decagon Inc.), temperature-dependent measurements are obtained using a thermal bath, and samples are thermally equilibrated before each measurement.

\section{MATERIALS AND EXPERIMENTAL DETAILS}

The experimental materials are lubricants directly applied on plastic deformation industrial processes, such as deep drawing, stamping, punching, and bending. The first conventional lubricant is Ecodraw (FUCHS, USA), which is a water-soluble synthetic lubricant for metalforming operations from light to heavy duty. The second analyzed lubricant is Montgomery (FUCHS, USA), which is a lubricant for severe stamping and deep drawing processes. Both lubricants are from FUCHS supplier (Table 1).The first stage of our research consists of preparing diluted concentrations of both lubricants (Table 2). Concentrations were selected according to industrial experience and supplier recommendations. General application in manufacturing processes for Ecodraw lubricant is 1:6 ratio, and for Montgomery lubricant is 1:4.
Table 1. Material properties and characteristics

\begin{tabular}{|c|c|c|}
\hline Materials & \multicolumn{2}{|c|}{ Properties } \\
\hline Base Lubricants & Density @ 15 $\mathbf{C}^{\circ}$ & General applied ratio \\
\hline EcoDraw & $1.08 \mathrm{~g} / \mathrm{cm}^{3}$ & $1: 6$ \\
\hline Montgonery & $0.99 \mathrm{~g} / \mathrm{cm}^{3}$ & $1: 4$ \\
\hline Nanostructures & \multicolumn{1}{|c|}{} \\
\hline h-BN & Morphology: 2D sheet structure \\
\hline & Size: 300nm by 300nm, 5 atomic layers \\
\hline Tribotest Balls & Chemical Composition \\
\hline Steel AISI 52100 & $\begin{array}{l}0.98-1.1 \% \mathrm{C}, 0.15-0.30 \% \mathrm{Si}, \\
0.25-0.45 \% \mathrm{Mn}, 1.30-1.60 \% \mathrm{Cr}\end{array}$ \\
\hline & Diameter: 12.7mm, 60 HRC \\
\hline Block \& Ring & \multicolumn{2}{|l}{$\begin{array}{l}\text { Heat treated (Quench + Tempered), } \\
58-62 \mathrm{HRC}\end{array}$} \\
\hline D2 Steel & \multicolumn{2}{|l}{} \\
\hline
\end{tabular}

Prepared lubricants were evaluated under EP conditions with a four-ball configuration, according to ITeE-PIB Polish method for testing lubricants under conditions of scuffing $[23,24]$. In this setting, three stationary steel balls are covered with the lubricant sample $(\sim 13 \mathrm{ml})$ whereas the upper ball rotates at $600 \mathrm{rpm}$ under linearly increasing load from 0 to $7200 \mathrm{~N}$ at room temperature $\left(24^{\circ} \mathrm{C}\right)$ for $18 \mathrm{~s}$.

The load carrying capacity $\left(\mathrm{p}_{\mathrm{oz}}\right.$ ) was obtained as follows: $\mathrm{p}_{\mathrm{oz}}=0.52\left(\mathrm{P}_{\mathrm{oz}} / \mathrm{WSD}^{2}\right)$, where $\mathrm{P}_{\mathrm{oz}}$ is the seizure load that occurs at a frictional torque of 10 N.m and WSD is the wear scar diameter of the three stationary steel balls. Three to six tests were performed for each set of lubricant concentration to obtain statistically significant results [25]. Wear scars of worn balls were measured through an Alicona optical 3D measurement system (Bruker, Germany). After the first stage of diluted lubricants evaluation, the highest performance material was selected as the base material to be reinforced with h-BN nanostructures. Results are displayed per lubricant concentration and $\mathrm{p}_{\mathrm{oz}}$ of lubricant film. The higher the $p_{o z}$ value, the better the performance of the lubricant under friction conditions.

Table 2. Lubricant's concentration ratio.

\begin{tabular}{|c|c|}
\hline \multicolumn{2}{|c|}{ Ecodraw } \\
\hline Ratio & $\begin{array}{c}\text { Concentration } \\
(\%)\end{array}$ \\
\hline $1: 5$ & 20 \\
\hline $1: 6$ & 16.7 \\
\hline $1: 7$ & 14 \\
\hline $1: 8$ & 12.5 \\
\hline $1: 10$ & 10 \\
\hline
\end{tabular}

\begin{tabular}{|c|c|}
\hline \multicolumn{2}{|c|}{ Montgomery } \\
\hline Ratio & $\begin{array}{c}\text { Concentration } \\
(\%)\end{array}$ \\
\hline $1: 3$ & 33 \\
\hline $1: 4$ & 25 \\
\hline $1: 5$ & 20 \\
\hline $1: 6$ & 16.7 \\
\hline $1: 8$ & 12.5 \\
\hline
\end{tabular}

2D-nanostructures of h-BN were obtained by wet exfoliation method, according to Taha-Tijerina et al. [15], powder-like material was homogeneously dispersed within the base lubricants at $0.10 \mathrm{wt} . \%$ through extensive water bath sonication (5 - $6 \mathrm{hr}$.), maintaining the water bath at a constant temperature 
$\left(<40^{\circ} \mathrm{C}\right)$. Material displays good shelf stability for at least 3-4 weeks [15].

Thermal conductivity measurements on dilutions and nanolubricants were carried out according to the transient hot-wire (THW) technique (Decagon, Inc. KD2 Pro). Temperature-dependent measurements were performed using a thermal water bath, in which specimens were initially thermally equilibrated for 6 minutes before each measurement. Obtained values are compared with base lubricant dilutions thermal conductivities $\left(\mathrm{k}_{0}\right)$. At least 7 measurements were taken for each nanolubricant to report averaged values.

\section{RESULTS AND DISCUSSIONS}

Results obtained for lubricants are shown in Figure 1 and Figure 2, respectively, using the ITEePib Polish method for calculating load-carrying capacity $\left(\mathrm{p}_{\mathrm{oz}}\right)$ at EP. For the Ecodraw lubricants, load-carrying capacity was affected by the present dilutions. Not taking in consideration due to costs implications, 1:5 ratio was just evaluated as comparison with other materials. The highest improvement reflected a $28 \%$ increase at 1:6 ratio, compared to the conventionally used concentration, this concentration was selected to be further reinforced with h-BN nanostructures.

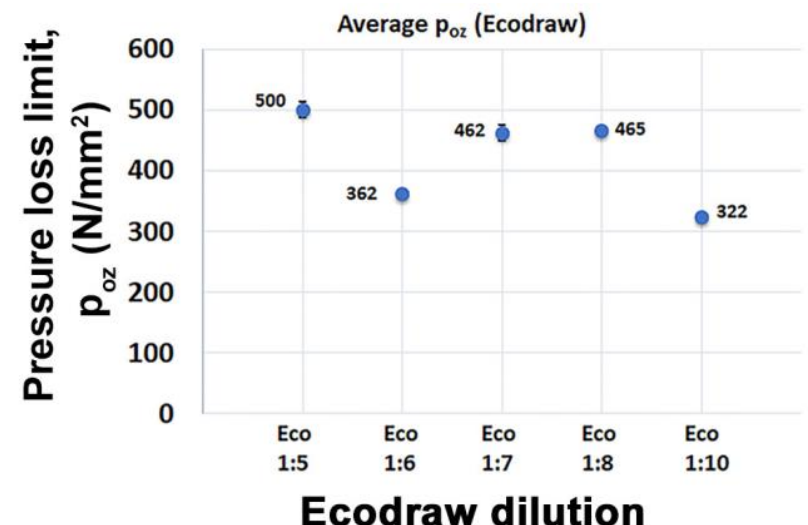

Fig 1. Load-carrying capacity $\left(\mathrm{p}_{\mathrm{oz}}\right.$ ) of diluted Ecodraw lubricant by the four-ball tribotester under EP

In a similar manner, Montgomery lubricants were analysed. In this case, the load-carrying capacity was not significantly affected. Only a 3\% improvement was observed at higher water content (1:6 ratio), which was the selected concentration for further h$\mathrm{BN}$ nanoreinforcement evaluation.

The next stage of our research consisted of homogeneously dispersing the 2D-nanostrucures of h-BN within the selected lubricant concentrations. Filler fraction of $0.10 \mathrm{wt} . \%$ of h-BN was chosen from previous research group studies to reinforce diluted lubricants. Glass vials $(40 \mathrm{ml})$ were used to contain the samples for extensive water bath sonication.

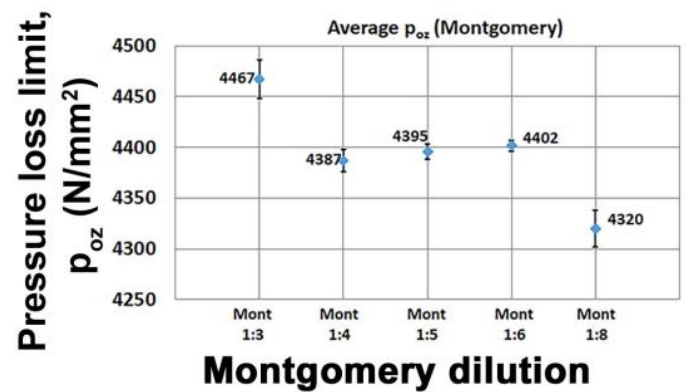

Fig. 2. Load-carrying capacity ( $\mathrm{p}_{\mathrm{oz}}$ ) of Montgomery lubricants by the four-ball tribotester under extreme pressures (EP)

In both cases, due to the presence of solid nanostructures, the frictional torque value was not reached, thus, the maximum load applied in the evaluations was taken as the seizure load $(7200 \mathrm{~N})$. For Ecodraw and Montgomery nanolubricants, 2D nanostructures of h-BN acted as promoter of tribofilm formation, creating a smoother surface or could provide a third-body effect, preventing bare metal to metal contact, improving the load-carrying capacity of the lubrication system. Additionally, block-on-ring configuration was selected to analyse the coefficient of friction (COF) in a friction pair, where both, block and ring, are D2 tool steel materials. Tribotesting was performed according to ASTM G77. Each specimen was evaluated for 900 seconds, at a constant load of $392 \mathrm{~N}$ and an angular velocity of 250 RPMs. Table 3 shows the COF results for base dilutions, optimized dilutions and h-BN reinforced nanolubricants.

Table 3. COF for Ecodraw and Montgomery nanoreinforcing

\begin{tabular}{|c|c|c|c|c|c|}
\hline \multicolumn{3}{|c|}{ Ecodraw } & \multicolumn{3}{c|}{ Montgomery } \\
\hline Ratio & COF & \% & Ratio & COF & \% \\
\hline Base $1: 6$ & 0.1337 & - & Base $1: 4$ & 0.1314 & - \\
\hline $1: 8$ & 0.1339 & -0.15 & $1: 6$ & 0.1325 & -0.83 \\
\hline $1: 8$ Nano & 0.1247 & 7.22 & $1: 6$ Nano & 0.1180 & 10.20 \\
\hline
\end{tabular}

EDAX analysis is shown in Figure 3. Here, it could be observed that Boron and Nitrogen elements are present in the wear scar obtained (Figure 3). This is mainly attributed to a tribosinterering phenomena of the $2 \mathrm{D}$ nanostructures to the surface of the metal component.

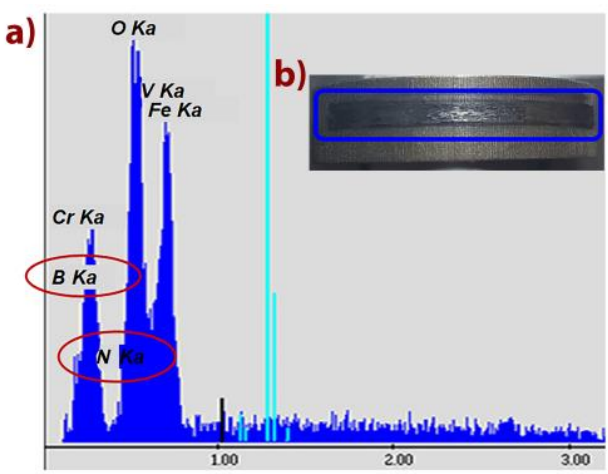

Fig. 3. a) EDAX of D2 steel ring, showing $\mathrm{B}$ and $\mathrm{N}$ from h-BN nanoreinforcement b) Ring wear scar after tribotest 
Figure 4(a) and Figure 4(b) show the TEM and SEM images of h-BN 2D-nanostructures, respectively. Figure 4(b) shows the wear scar on one of the bottom steel balls after tribology evaluation. A 2D h-BN nanosheet is shown on the surface of tested steel ball in Figure 4(b), as also shown in Figure 3 for EDAX analysis.
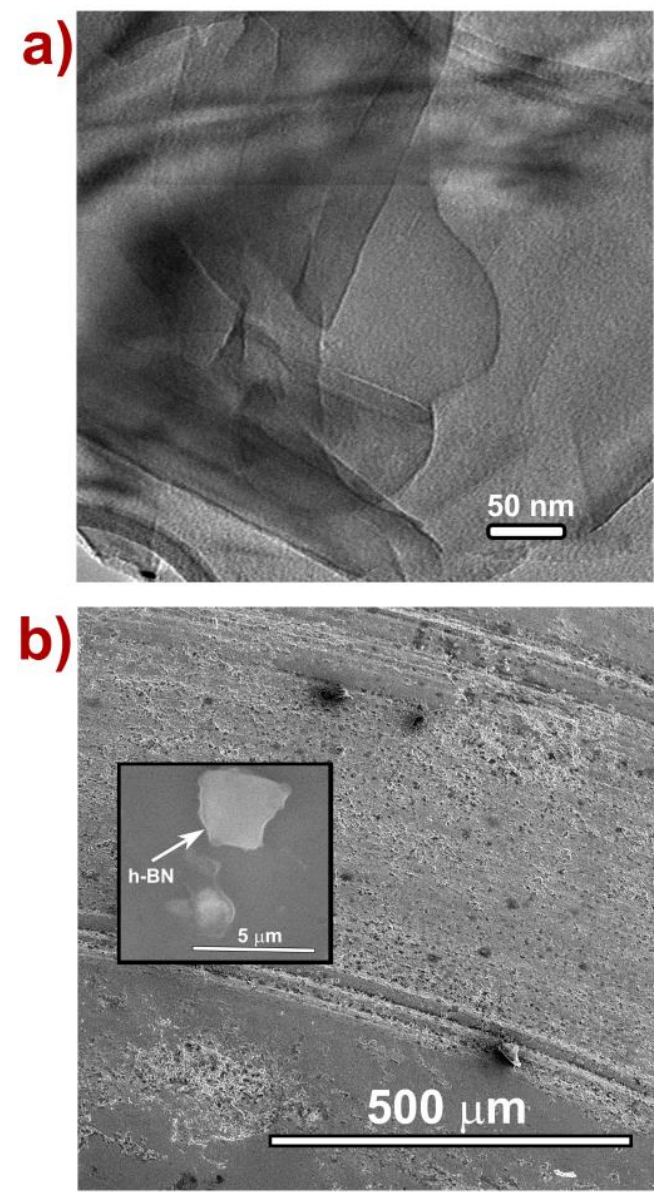

Fig. 4. a) TEM image of 2D h-BN nanostructures. (b) SEM image of evaluated steel ball showing the wear scar, in the inset it could bee observed h-BN flakes on wear scar

Finally, thermal conductivity measurements were performed to determine the effect of $2 \mathrm{D} h-\mathrm{BN}$ nanoreinforcement on lubricant dilutions. Figure 5 shows the improvement in thermal conductivity for Ecodraw and Montgomery. For both lubricants, base dilutions did not show significant increase in thermal conductivity as temperature was raised up to $323 \mathrm{~K}$. Nanolubricants showed a temperature-dependent variation, indicating the effect of incorporation of $h$ BN. Effective thermal conductivity $\left(\mathrm{k}_{\mathrm{eff}}\right)$ of nanolubricants increased with temperature raise (measurements were made from room temperature $\sim 298 \mathrm{~K}$ up to $323 \mathrm{~K}$ ), indicating the role of Brownian motion on measured thermal conductivities. For instance, for Ecodraw lubricant, h-BN had a very positive effect on performance, with merely $0.10 \mathrm{wt} . \%$ reinforcement, reaching up to $30 \%$ increase when compared to bare Ecodraw dilution. In the case of Montgomery lubricant, the effect was positive too. Here, we observed an increase of about $15 \%$, when compared to Montgomery dilution. Measurements showed a variation of $2-3.5 \%$. Therefore, the error bars are not visible in Figure 5.

Thermal transport performance of 2D-reinforced nanolubricants is originated by diverse mechanisms, such as percolation channel formation, liquid-particle layering, van der Waals effects, among others. Partilarly, the liquid layering at the nanostructurelubricant interface is predicted as the most important mechanism for effective thermal conductivity enhancement in nanolubricants [6,26,27]. Additionally, the temperature-dependent variations in thermal conductivity indicate that not only the percolation mechanism affects the improvement in thermal conductivity, but also the Brownian motion contributes to the behavior of h-BN 2D-based nanolubricants.

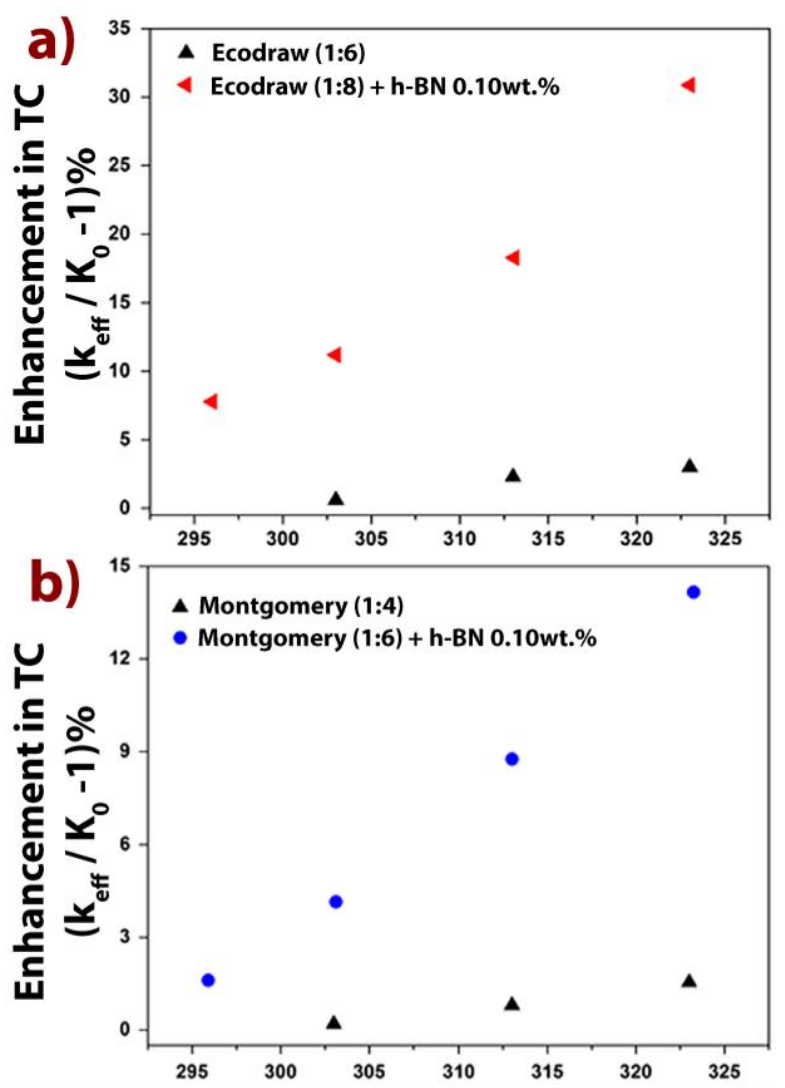

Fig. 5. Thermal conductivity improvement for a) Ecodraw and b) Montgomery lubricants with and without h-BN nanoreinforcement at various temperatures (Kelvin degrees)

\section{CONCLUSIONS}

The analysed lubricant dilutions and nanolubricants have the potential to be used as good alternative material for plastic formation processes in metalmechanic field. In this work, the tribological 
properties of lubricant dilutions were observed. Furthermore, from the optimized concentration of lubricants, h-BN nanostructures were homogenously dispersed as reinforcement at $0.10 \mathrm{wt} . \%$, based on previous research by authors. It was found that h-BN contributed significantly to load carrying capacity (poz) improvement at this filler fraction, representing an improvement of 7 and $10 \%$ for Ecodraw and Montgomery lubricant dilutions, respectively. This was attributed to a third-body mechanism and promotion of tribofilm formation, creating a smoother surface, thus reducing friction. Additionally, heat generation while working among metals and plastic deformation is a critical issue. Thermal conductivity measured at various temperatures showed an improvement of 30 and $15 \%$ for Ecodraw and Montgomery optimized dilutions, respectively, with h-BN reinforcement.

\section{ACKNOWLEDGEMENTS}

Authors would like to acknowledge Universidad de Monterrey for their support.

\section{REFERENCES}

1. Davim, J.P. (2013) Tribology in Manufacturing Technology Materials Forming, Machining and Tribology). Springer Berlin Heidelberg

2. Schmid, S.R., Saha, P.K., Wang, J., Schmitz, T. (2020) Developments in Tribology of Manufacturing Processes. J. Manuf. Sci. Eng. 142(11), pp. 110803.

3. Kandile, N.G., Harding, D.R.K. (2019) A Green Approach to Tribology. Surfactants in Tribology. pp. 215-266, CRC Press (Boca Raton).

4. Shahnazar, S., Bagheri, S., Abd Hamid, S.B. (2016) Enhancing lubricant properties by nanoparticle additives. Int. J. Hydrogen Energy. 41(4), pp. 3153-3170.

5. Taha-Tijerina, J., Aviña, K., Diabb, J.M. (2019) Tribological and Thermal Transport Performance of $\mathrm{SiO}_{2}$-Based Natural Lubricants. Lubricants 7, pp. 71

6. Taha-Tijerina, J., Ribeiro, H., Aviña, K., Martínez, J.M., Godoy, A.P., Cremonezzi, J.M. de O., (2021) Thermal Conductivity Performance of $2 D h$ BN/MoS 2 -Hybrid Nanostructures Used on Natural and Synthetic Esters Nanomaterials, 10, pp. 1160

7. Pena-Paras, L., Gutiérrez, J., Irigoyen, M., Lozano, M., Velarde, M., Maldonado-Cortes, D.,TahaTijerina, J. (2018) Study on the anti-wear properties of metal-forming lubricants with $\mathrm{TiO}_{2}$ and $\mathrm{CuO}$ nanoparticle additives. IOP Conf. Ser. Mater. Sci. Eng. 400, pp. 062022.

8. Taha-Tijerina, J., Shaji, S., Sharma, S., MendivilPalma, M.I., Aviña, K. (2020) Tribological and Thermal Transport of Ag-Vegetable Nanofluids
Prepared by Laser Ablation Appl. Sci. 10, pp. 1779 9. Sharma, K.A., Tiwari, A.K., Dixit, A.R. (2015) Mechanism of Nanoparticles functioning and Effects in Machining Processes: A review. Mater. Today Proc. 2, pp. 3539 - 3344.

10. Song, X., Zheng, S., Zhang, J., Li, W., Chen, Q, Cao, B. (2012) Synthesis of monodispersed $\mathrm{ZnAl}_{2} \mathrm{O}_{4}$ nanoparticles and their tribology properties as lubricant additives. Mater. Res. Bull. 47, pp. 4305 4310

11. Singh, A., Chauhan, P., Mamatha, T.G. (2019) A review on tribological performance of lubricants with nanoparticles additives.Materials Today: Proceedings. pp. 586-591, Elsevier Ltd.

12. López, T.D.-F., González, A.F., Del Reguero, Á., Matos, M., Díaz-García, M.E., Badía-Laíño, R. (2015) Engineered silica nanoparticles as additives in lubricant oils. Sci. Technol. Adv. Mater. 16, pp. 055005.

13. Peña-Parás, L., Maldonado-Cortés, D., TahaTijerina J. (2018) Eco-Friendly Nanoparticle Additives for Lubricants and Their Tribological Characterization. Handbook of Ecomaterials, pp. 121. Cham: Springer International Publishing (Switzerland)

14. Taha-Tijerina, J., Castillo, F., Leal, J., Peña-Parás, L., Demófilo, M.-C., Cruz, C., (2018) Nanoparticles of $\mathrm{Zn}$ and $\mathrm{ZnO}$ as extreme pressure (EP) additives for lubricants. J. Appl. Res. Technol. 16, pp. 394 - 403

15. Taha-Tijerina, J., Peña-Paras, L., Narayanan, T.N., Garza, L., Lapray, C., Gonzalez, J., (2013) Multifunctional nanofluids with $2 D$ nanosheets for thermal and tribological management. Wear. 302(12), pp. 1241-1248.

16. Taha-Tijerina, J., Narayanan, T.N., Gao, G., Rohde, M., Tsentalovich, D.A., Pasquali, M., Ajayan, P.M. (2012) Electrically insulating thermal nano-oils using 2D fillers. ACS Nano. 6(2), pp. 1214-1220.

17. Wang, J., Ma, F., Sun, M. (2017) Graphene, hexagonal boron nitride, and their heterostructures: properties and applications RSC Adv. 7, pp. 16801 16822

18. Wan, Q., Jin, Y., Sun, P., Ding, Y. (2015) Tribological behaviour of a lubricant oil containing boron nitride nanoparticles. In: Procedia Engineering. Elsevier Ltd. p. 1038-1045.

19. Çelik, O.N., Ay, N., Göncü, Y. (2013) Effect of nano hexagonal boron nitride lubricant additives on the friction and wear properties of AISI 4140 steel. Part. Sci. Technol. 31(5), pp. 501-506.

20. Río, J.M.L., López, E.R., Fernández, J. (2021) Tribological properties of graphene nanoplatelets or boron nitride nanoparticles as additives of a polyalphaolefin base oil. J. Mol. Liq. 333, pp. 115911 21. Peña-Parás, L., Maldonado, D., Taha-Tijerina, J. (2019) Eco-friendly nanoparticle additives for lubricants and their tribological characterization. 5, 
Handbook of Ecomaterials. Springer, Switzerland.

22. Abdollah, M.F.Bin, Amiruddin, H., Jamallulil, A.D. (2020) Experimental analysis of tribological performance of palm oil blended with hexagonal boron nitride nanoparticles as an environmentfriendly lubricant. Int. J. Adv. Manuf. Technol. 106(9), pp. 4183-4191

23. Szczerek. M., Tuszynski, W. (2002) A method for testing lubricants under conditions of scuffing. Part I. Presentation of the method. Tribotest. 8(4), pp. 273 284

24. Piekoszewski, W., Szczerek, M., Tuszynski, W. (2002) A method for testing lubricants under conditions of scuffing. Part II. The anti-seizure action of lubricating oils. Tribotest. 9(1), pp. 35-48.

25. Dean, R.B., Dixon, W.J. (1951) Simplified Statistics for Small Numbers of Observations. Anal. Chem. 23(4), pp. 636 - 638

26. Baby, T.T., Sundara, R. (2011) Synthesis and Transport Properties of Metal Oxide Decorated Graphene Dispersed Nanofluids. J. Phys. Chem. C. 115(17), pp. 8527-8533.

27. Shima, P.D., Philip, J., Raj, B. (2010) Synthesis of Aqueous and Nonaqueous Iron Oxide Nanofluids and Study of Temperature Dependence on Thermal Conductivity and Viscosity. J. Phys. Chem. C. 114(44), pp. 18825-18833. 